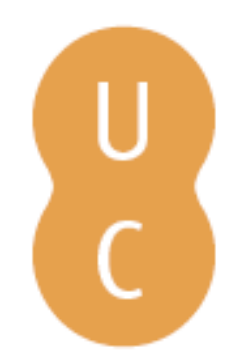

\title{
pommalina
}

\section{As estruturas de conhecimento de responsáveis bancários sobre organização: estudos de mapeamento cognitivo}

Autor(es): Jordão, Filomena

Publicado por: Imprensa da Universidade de Coimbra

URL

persistente: URI:http://hdl.handle.net/10316.2/32741

DOI: $\quad$ DOI:http://dx.doi.org/10.14195/978-989-26-0452-7_1

Accessed : $\quad$ 26-Apr-2023 12:23:47

A navegação consulta e descarregamento dos títulos inseridos nas Bibliotecas Digitais UC Digitalis, UC Pombalina e UC Impactum, pressupõem a aceitação plena e sem reservas dos Termos e Condições de Uso destas Bibliotecas Digitais, disponíveis em https://digitalis.uc.pt/pt-pt/termos.

Conforme exposto nos referidos Termos e Condições de Uso, o descarregamento de títulos de acesso restrito requer uma licença válida de autorização devendo o utilizador aceder ao(s) documento(s) a partir de um endereço de IP da instituição detentora da supramencionada licença.

Ao utilizador é apenas permitido o descarregamento para uso pessoal, pelo que o emprego do(s) título(s) descarregado(s) para outro fim, designadamente comercial, carece de autorização do respetivo autor ou editor da obra.

Na medida em que todas as obras da UC Digitalis se encontram protegidas pelo Código do Direito de Autor e Direitos Conexos e demais legislação aplicável, toda a cópia, parcial ou total, deste documento, nos casos em que é legalmente admitida, deverá conter ou fazer-se acompanhar por este aviso.

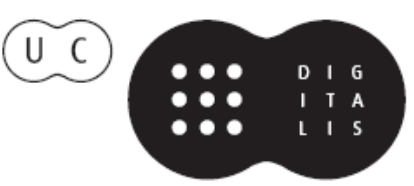




\section{A. DUARTE GOMES - ANTÓNIO CAETANO JOSÉ KEATING • MIGUEL PINA E CUNHA

\author{
Coordenadores
}

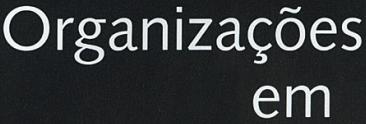

Transição

Contributo da Psicologia do Trabalho

e das Organizaçōes 
(Página deixada propositadamente em branco) 


\section{A. DUARTE GOMES - JOSÉ KEATING ANTÓNIO CAETANO - MIGUEL PINA E CUNHA Coordenadores}

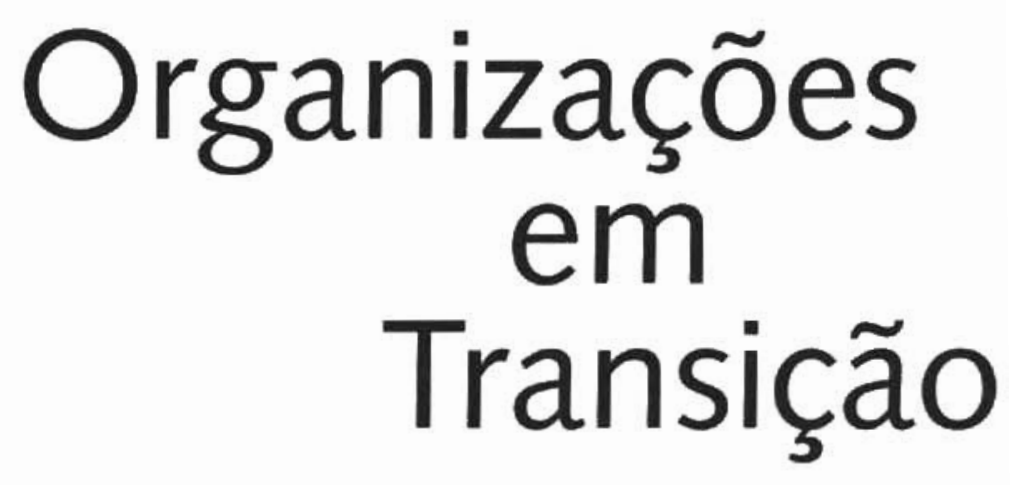

Contributos da Psicologia do Trabalho e das Organizações 


\section{COORDENACÁO EDITORIAL \\ Imprensa da Universidade de Coimbra \\ CONCEPÇÃO GRAFACA \\ António Barros \\ EXECUÇÃO GRAFICA \\ G.C. - Gráfica de Coimbra, Lda. \\ Palheira - Assafarge - Apart. 3068 \\ 3001-453 Coimbra Codex}

ISBN

972-98225-3-0

DEPOSITO LEGAL.

153435/00

(c) JunHo 2000. Imprensa da Universidade de Coimbra 


\title{
AS ESTRUTURAS DE CONHECIMENTO DE RESPONSÁVEIS BANCÁRIOS SOBRE ORGANIZAÇÃO: ESTUDOS DE MAPEAMENTO COGNITIVO(I)
}

\author{
FILOMENA JORDÃO \\ FACULDADE DE PSICOLOGIA E DE CIENCIAS DA EDUCAÇÃO \\ DA UNIVERSIDADE DO PORTO
}

\section{INTRODUÇÃO}

Inserindo-se numa perspectiva cognitivista do estudo das Organizações, este trabalho pretende investigar a vertente cognitiva da estruturação organizacional. Assumindo o pressuposto de que as Organizações bem como os fenómenos que nelas ocorrem são cognitivamente construídos pelos seus actores, consideramos que as formas organizativas são soluções que visam responder às características e exigências ambientais quer internas (tecnológicas, de pessoal), quer externas (por ex.. competitividade) à Organização, tal como estas são interpretadas pelos agentes responsáveis pela "organização" ou "estruturação organizacional" nas Organizações.

Particularmente importante para a temática em estudo e para a forma como desenvolvemos este trabalho foi a proposta de sistematização das teorias das Organizações e da Gestão apresentada por Astley e Van de Ven (1983). Os autores para além de proporem uma sistematização conjunta des-

(1) Este estudo constitul um dos estudos empíricos que integram a tese de doutoramento da autora, apresentada na Faculdade de Psicologia e de Ciências da Educação da Universidade do Porto em Novembro de 1998. 
tas teorias, definem num esforço de integração das quatro visões daí resultantes(2), seis debates sobre a natureza e estruturação das Organizações que na sua opinião, têm caracterizado este campo de estudos. Dois destes debates foram por nós considerados e explorados ao longo deste trabalho servindo-Ihe de guia orientador.

O primeiro destes debates é o relativo à natureza das Organizações através do qual se questiona se as Organizações são sistemas funcionalmente racionais e tecnicamente constrangidos, ou se são realidades socialmente construídas, isto é, personificações subjectivamente compreensíveis da acção individual (Astley \& Van de Ven, 1983).

Esta questão coloca-nos perante alguns dos pressupostos subjacentes a dois dos paradigmas definidos por Burrell e Morgan (1979), o paradigma "funcionalista" - aquele que tradicionalmente tem servido de suporte à maior parte dos estudos organizacionais —, e o paradigma "interpretativo", o paradigma emergente neste domínio de estudos a partir da década de setenta/oitenta. De facto, o estudo das Organizações desenvolveu-se até esta altura, na base duma perspectiva «objectivista», «racional» (Benson, 1977), «funcionalista» (Burrell \& Morgan, 1979. Morgan, 1983, 1986, 1989) ou "entitativa" (Hosking \& Morley, 1991). Perspectiva segundo a qual as Organizações e qualquer um dos seus fenómenos são entendidos como entidades objectivas, passiveis de conhecimento por observadores externos e independentes daquela e por estas duas razões, se considera que as Organizações são avaliáveis através de procedimentos experimentais precisos e concretos.

Também o estudo das formas organizativas ou estruturais assumidas pelas Organizações tem sido tradicionalmente dominado tal como a maioria das temáticas inseridas neste campo de estudos, pela perspectiva racionalista ou funcionalista e "entitativa". De facto, a estrutura e o meio organizacional têm sido considerados entidades objectivas, concretas e para além de tudo, independentes uma da outra.

8 Nos finais da década de setenta, uma outra perspectiva começa a emergir no estudo dos fenómenos sociais nomeadamente no estudo das Organizações, a perspectiva «cognitivista» que realça o carácter sociocognitivamente construído das concepçōes organizacionais (Peiró, 1990), ou seja, começa a

(2) Referimo-nos à visão ou perspectiva estrutural - sistémica, à da escolha estratégica, à da selecção natural e à da acção colectiva de Organização e Gestão. 
considerar-se a participação que ao nivel cognitivo, cada actor organizacional tem na definição do que posteriormente reconhece como a realidade orgonizocional. $\mathrm{O}$ aparecimento desta perspectiva que veio a provocar aquilo que Scott denominou como o «desmantelamento parcial da catedral dominante da estrutura racional» (Scott, 1987: xv). pôs em relevo uma situação de crise a exigir uma mudança nos pressupostos paradigmáticos até aí predominantes (Peiró, 1990) no estudo da realidade organizacional. De facto, e segundo Morgan os investigadores inseridos nesta perspectiva emergente, «não procuram mais generalizar «factos» que assentam na operacionalização de leis deduzidas da natureza, mas em suscitar, a partir de estudos em profundidade de casos únicos, «tomadas de consciência» que permitam compreender melhor situações particulares que se produzem em outros contextos ou Organizações» (Morgan, 1985 citado em Cossette, 1994b: 5).

Um dos primeiros autores a conceptualizar teoricamente esta perspectiva foi Weick (1979)(3) para quem as Organizações não possuem uma «realidade» subjacente à espera de ser descoberta mas «constituem antes invenções elou criações das pessoas» (Weick, 1979: 12). Foi com base neste modelo teórico genericamente conhecido por Teoria do organizing ou Teoria do processo de organizar, com cujas premissas nos identificamos, que realizámos o trabalho aqui apresentado.

O autor propõe um modelo das Organizações em que estas são consideradas «sistemas de interpretação» ou «sistemas de significados», que para sobreviver devem possuir mecanismos que lhes permitam interpretar acontecimentos ambíguos e dar ou atribuir sentido e direç̧ão aos seus participantes (Weick, 1979. 1990, 1995). O conceito fulcral da sua abordagem é o de «organizing», conceito que traduz não só a característica dinâmica da realidade em estudo, como evidencia a natureza exclusivamente humana e interpretativa desta actividade. $\mathrm{O}$ autor entende $\mathrm{O}$ 《organizing» como «uma gramática consensualmente validada para reduzir a ambiguidade através de comportamentos entrecruzados» (Weick, 1979: 3) correspondendo assim, a um processo de construção permanente de significação organizacional, constituído por quatro processos básicos: (1) o processo de mudanças ou transformações ecológicas, (2) o processo de «enactment»)(4), (3) o processo de

(3) Data da $2^{2}$ edição da obra publicada inicialmente em 1969.

(4) Dada a especificidade que este termo assume neste modeio e a nossa dificuldade em encontrar um termo português que traduzisse toda a sua niqueza, optámos por nāo o traduzir 
selecção e, finalmente (4) o processo de retenção. É na dinâmica interactiva destes quatro processos que se constitui o processo de «organizing» sintetizado por Weick da seguinte forma: os meios com os quais as pessoas e/ou as Organizações interagem são o resultado de um processo através do qual elas destacam e/ou focalizam do meio (actividade de uenactment») uma dada porção da experiência (aquela que corresponde essencialmente às transformações e às diferenças que os fluxos de experiência apresentam), impõem uma série finita de interpretações a esta porção da experiência (actividade de selecção) e, finalmente, procedem ao armazenamento de segmentos interpretados para futura aplicação em situações semelhantes (actividade de retenção) (Weick, 1979, 1995).

Desta forma, assumir as Organizações como sistemas sociocognitivamente construídos influencia a compreensão que se faz do papel dos actores organizacionais: o seu comportamento é visto como essencialmente proactivo e não já como sendo determinado pelo meio e reactivo a este como o era na perspectiva mais tradicional. $O$ que ao nível macro, implica assumir que a vida organizacional é uma criação activa resultante de escolhas estratégicas da gestão e de outros actores organizacionais significativos e não é determinada por constrangimentos ambientais reais, concretos. Ou seja, estamos perante outro dos debates relativos à natureza e estruturação organizacional definidos por Astley e Van de Ven, que é o relativo aos determinantes da vida organizacional (Astley \& Van de Ven, 1983).

É neste contexto que se começa a considerar a participação de um outro tipo de variáveis no processo de organizar, as variáveis relacionadas com os agentes a quem por definição cabe esta tarefa organizacional. Assim, o factor de «design» (Hall, 1987) começa a ser considerado como relevante na forma organizativa assumida pelas Organizações. Ou seja, as formas organizativas são entendidas como o resultado de escolhas feitas por aqueles que na Organização estão investidos de poder para influenciar o seu curso de

10 acções. Considerando o processo de (r)estruturação organizacional como um processo de escolhas, os diferentes modos de organização deverão assim, deixar de ser vistos como dados adquiridos ou como fatalismos deterministas.

ao longo deste trabalho. Autores de língua francesa (por ex. Cossette, 1989) optaram pela tradução francesa «engagement dans le réel», cuja tradução para português não nos parece corresponder também à riqueza do conceito original inglês. 
mas antes como soluções construídas, logo, artificiais (Crozier \& Friedberg, 1977), que determinados actores organizacionais — os que possuem poder para tal — propõem e actualizam. Sabendo que estes responsáveis escolhem e agem em domínios ambientais de acordo com concepções que constróem acerca de como o meio é (Morgan, 1986; 1989), consideramos que a forma como as características e exigências do meio interno e externo da Organização são lidas, interpretadas, afinal «enoctodos» pelos responsáveis dos processos de restruturação organizacional, desempenha um papel preponderante nestes processos.

Desta forma, os actores organizacionais são considerados como «processadores de informação» (Walsh, 1989; Mintzberg, 1982) que ao nível cognitivo desenvolvem estruturas de conhecimento - conceito chave da perspectiva "top-down" ou «theory driven» de processamento de informação (Abelson \& Black, 1986) - que os ajudam não só a atribuir significado ao mundo que os rodeia, a organizá-lo cognitivamente, como também a simplificá-lo; o «meio organizacional» é entendido como um produto enactado que se localiza nos esquemas ou estruturas de conhecimento dos gestores (Stubbart \& Ramaprasad, 1988). Ou seja, enquanto que logicamente podemos falar nas categorias interno/externo ou interiorlexterior relativas ao meio organizacional, empiricamente consideramos que estas categorias não existem. A este propósito, partilhamos inteiramente com Weick a ideia de que apenas existe o interior (o exterior é um vazio), e que tudo o que pode ser conhecido é a visão interna ou o interior do mundo de uma pessoa (Weick, 1982: 273).

Assim, numa perspectiva interpretativa ou cognitivista da estruturação organizacional, torna-se imprescindivel conhecer a forma como as características do meio organizacional são lidas, interpretadas, afinal «enactadas» pelos gestores e elementos do topo da tecnoestrutura (Mintzberg, 1982, 1990), detentores do poder formal para "organizar" em instituições nacionais de crédito.

\section{METODOLOGIA DO ESTUDO EMPIRICO}

Dado que o nosso objecto de estudo é intrinsecamente cognitivo, isto é. são as estruturas de conhecimento que responsáveis bancários possuem sobre "organização", optámos pela metodologia de mapeamento cognitivo. A partir do momento que se opta pelo mapeamento cognitivo como metodolo- 
gia de investigação, tem de se assumir uma série de opções, paralelamente às decisões de desenho que habitualmente se assumem em qualquer investigação. Assim por ex., é importante a definição clara do objectivo da elaboração do mapa assim como do território que ele cobrirá ou abrangerá (Huff \& Fletcher, 1990). É da definição ou clarificação destes aspectos que nos ocuparemos a seguir.

\section{Objectivos}

No estudo aqui apresentado, um estudo de cosos múltiplos descritivos (Yin. 1993. 1994), procurámos explorar o que pensam e como pensam responsáveis bancários sobre organização e quais as variáveis ou que factores eles consideram afectar este processo. Ou seja, este estudo centra-se no processo de enactment do ambiente (Weick, 1979, 1982) isto é, na forma como os intervenientes em processos de (r)estruturação organizacional criam os meios com que se confrontam e que aceitam posteriormente como sendo exteriores a si. A prossecução deste objectivo implica de acordo com alguns autores (Lord \& Kernan, 1987; Walsh \& Fahey, 1986; Walsh, 1989), não só a descrição do conteúdo das estruturas de conhecimento que responsáveis bancários sustentam sobre organização ou estruturação organizacional, como também a especificação da estrutura subjacente àquele conhecimento, isto é, a elaboração de mapas cognitivos para cada um dos entrevistados.

\section{Especificações do território a representar graficamente}

Segundo Erdener e Dunn a decisão mais básica que tem que se tomar quando se recorre ao método de mapeamento cognitivo envolve a escolha entre um mapa que reflicta a cognição individual ou um que reflicta as percepções partilhadas de um grupo e/ou Organização (Erdener \& Dunn, 1990). Nesta decisão, que se reflecte directamente na definição da amostra de estudo, desempenham obviamente, papel fundamental o(s) objectivo(s) do

12 estudo (definidos anteriormente) e as questões de investigação em análise. É sobre estes aspectos que nos debruçaremos a seguir.

As questôes de investigação

A questão básica de investigação para este estudo coloca-se ao nível individual e é a seguinte: «Qual é o conhecimento que bancários responsáveis pela estruturação ou restruturação organizacional possuem sobre "organização"? 
Entretanto, tendo em atenção os aspectos naturalmente salientados pelos entrevistados bem como as áreas de exploração do estudo exploratório(5) que se mostraram bastante eficazes na estimulação do discurso dos responsáveis bancários sobre a temática em estudo, podemos especificar esta questão nas seguintes:

a) Que dimensões do meio organizacional são relacionadas com organização?

b) Que tipo de factores "organizacionais" os responsáveis bancários consideram?

c) Como é que os entrevistados interpretam a influência do meio externo. nas suas opções de restruturação organizacional?

d) Que elementos do meio externo eles salientam?

e) Como é que os entrevistados interpretam a influência da tecnologia, nas escolhas organizativas que fazem?

f) Que aspectos tecnológicas eles salientam?

g) Como é que os entrevistados interpretam a influência do factor "pessoal/humano", nas suas opções de restruturação organizacional?

h) Que dimensões pessoais/humanas eles salientam?

i) Como é que os entrevistados interpretam a influência entre aspectos do meio externo e as variáveis de "tecnologia"?

j) Como é que os entrevistados interpretam a influência entre aspectos do meio externo e as variáveis de "pessoal"?

k) Como é que os entrevistados interpretam a influência entre os aspectos tecnológicos e as variáveis de "pessoal"?

1) Como é que os entrevistados interpretam a influência interactiva das diversas variáveis, isto é, quais as suas teorias ou o seu conhecimento sobre "organização"?

Niveis de análise

Como facilmente se depreende do que ficou dito anteriormente, o nivel de análise neste estudo é o individual, isto é, cada elemento, gestor elou téc. nico, que em Organizações de crédito portuguesas é responsável pelos pro-

(5): Este estudo foi precedido de um outro exploratório com o qual nos propunhamo. nos entre outros objectivos, exactamente o de elaborar um modelo de entrevista sem estruturada a ser utilizado na recolha de dados do estudo aqui apresentado. 
cessos de organização ou restruturação organizacional. Para tal, e como a restruturação dos balcões era um processo que decorria ou tinha decorrido há pouco tempo, optámos por seleccionar alguns intervenientes neste processo.

Neste tipo de Organizações o processo relativo à restruturação dos balcões envolve um conjunto de intervenientes organizacionais situados hierarquicamente no topo estratégico (Mintzberg, 1982, 1990) e no topo da tecnoestrutura (Mintzberg, 1982. 1990), isto é, implica a constituição de uma "constelação de trabalho" (Mintzberg, 1982) especificamente para este fim que uma vez alcançado, permitirá o "desfazer" da constelação criada.

Estando nós mais interessados no estudo em profundidade de casos individuais do que em análises mais superficiais de um grande número de sujeitos, optámos por um estudo mais intensivo do que extensivo (Cossette, 1989) tendo considerado um número restrito de casos. Além disso, ao realizarmos um estudo com casos múltiplos não tínhamos qualquer preocupação de «amostragem» mas, pretendíamos antes, utilizá-los numa lógica de replicação (Yin, 1993) de realidades que presumimos semelhantes. A sua utilização permitir-nos-á o estabelecimento de leituras comparativas sempre enriquecedoras nestes casos.

Assim, dos responsáveis gestores e técnicos, pela área da "organização" contactados em quatro Organizações onde decorria o processo de restruturação das suas agências ou balcões, conseguimos em tempo útil, a adesão de dois administradores e três elementos do topo da tecnoestrutura, num total de cinco casos. As principais características destes cinco elementos, todos do sexo masculino, foram agrupadas em duas dimensões: uma primeira relativa à formação e função desempenhada na Organização e uma segunda, relativa à Experiência no domínio da uorganização".

Relativamente à primeira destas dimensões podemos destacar que apenas um dos entrevistados não possúa formação superior, e que os restantes tinham formações superiores nos domínios da Economia (os dois administradores responsáveis pelo pelouro da organização), da Engenharia e da Matemática.

Quanto à Experiência no domínio da uorganizaçõo» pudemos constatar que a totalidade dos entrevistados tem cinco ou mais anos de experiência no domínio da «organização».

\section{Outras características relevantes do território}

Dois outros aspectos, são habitualmente considerados quando se decide pelo mapeamento cognitivo, um é relativo ao tipo de conteúdos da cognição 
que desejamos incluir no mapa e, o outro, intimamente relacionado com este, tem a ver com a quantidade de informação que nele pretendemos incluir.

$\mathrm{Na}$ resposta a ambas as questões vai desempenhar papel fundamental quer o objectivo do mapeamento como as questões de investigação delineadas, devendo «o que elabora o mapa encontrar formas de seleccionar apenas os conceitos e crenças que são relevantes para o estudo») (Eden, Jones \& Sims, 1983: 47). Segundo estes autores, e de acordo com a abordagem teórica subjacente ao método de mapeamento cognitivo que propõem, a Teoria dos Constructos Pessoais (Kelly, 1963), o entrevistador e/ou o investigador deverá tentar compreender a forma como o entrevistado caracteriza o problema ou a temática em estudo tentando assegurar-se que as ideias que se relacionam com valores e objectivos sejam incluídos no mapa. Desta forma, procurámos salientar do discurso dos entrevistados as suas ideias sobre "organização" quer eles se referissem a esta temática isoladamente ou a relacionassem com outros aspectos.

Em síntese, pretendemos neste estudo a elaboração de mapas cognitivos individuais que reflictam o conhecimento ou a(s) estrutura(s) de conhecimento que diversos e diferentes responsáveis pela "organização" em Instituições de crédito portuguesas sustentam.

\section{Técnicas de recolha de dados}

Porque a linguagem falada ou escrita pode ser considerada como um veículo privilegiado de acesso aos processos cognitivos individuais, não podendo por isso, deles ser separada, consideramos que «os dados de interesse na descoberta das teorias implícitas dos individuos são as suas comunicações, qualquer que seja a forma assumida, em relação ao constructo sob investigação» (Sternberg, 1985: p. 608). Quando o foco de análise é a linguagem ou o discurso do indivíduo, as fontes de recolha de dados podem ser basicamente (a) situações forjadas pelo investigador (por ex., entrevistas), (b) situações naturais como por ex., comunicações, discursos proferidos fora da situação de investigação ou, (c) arquivos (textos escritos pelos indivíduos sobre o tema em estudo).

Optámos neste estudo, pela recolha exclusiva de dados de entrevista «registos interactivos» (Walsh, 1989) - dada a ausência quer de textos escritos pelos próprios sobre o tema quer de ocasiões públicas (por ex., conferências, palestras) de exposição das suas ideias neste domínio. Além disso, consideramos a entrevista como o método que "melhor permite abordar a realidade, a verdade dos outros" (Grawitz, 1986). 


\section{Procedimento}

Os dados foram recolhidos em duas entrevistas, uma primeira entrevista (semi estruturada) que denominámos por "entrevista inicial" e, uma segunda entrevista mais estruturada que denominámos por "entrevista de validação". Estas entrevistas tiveram a duração média de $1: 30 \mathrm{H}$ e foram realizadas respectivamente, em Fevereiro e Abril de 1995, no contexto da Organização de pertença dos entrevistados.

Com a entrevista inicial pretendíamos basicamente recolher dados relativos ao modo como os entrevistados abordam as questōes de «organização» e como as relacionam com outras, dados afinal da realidade «subjectiva» (Pagès et al., 1984) de cada entrevistado.

Esta entrevista estava estruturada em duas partes: uma primeira parte, introdutória, èm que sinteticamente, era explicado o objectivo do estudo, solicitada a colaboração do entrevistado e garantido o sigilo das informações fornecidas; e, uma segunda parte, em que procurávamos explorar basicamente as estruturas de conhecimento que cada entrevistado possuía relativamente ao processo de "organização". Para tal, o entrevistado era por ex.. questionado sobre o que entendia por "organização»; que aspectos considerava associados às questões de «organização»; qual o papel que atribui ao meio externo, como por ex., a importância dos clientes e dos outros bancos a operar no mercado, nas formas organizativas assumidas; qual a importância atribuída aos aspectos relacionados com o "pessoal"; etc. Caso se mostrasse facilitador do discurso, sugeria-se aos entrevistados que verbalizassem sobre uma realidade objectiva nomeadamente, a restruturação recente dos balcões processo no qual estiveram envolvidos.

'Ao longo desta entrevista eram ainda explorados alguns dados demográficos dos entrevistados como por ex., a sua formação académica, se possuíam algum curso de gestão, os anos que estavam no cargo que desempenhavam, a experiência no domínio da «organização» antes da ocupação do actual cargo, aspectos que considerámos como potencialmente interessantes aquando da

16 interpretação dos resultados deste estudo.

Com a entrevisto de validação pretendíamos uma melhor exploração do que $o$ entrevistado pensa sobre a temática em estudo, pois a combinação de dados recolhidos em diferentes ocasiões permite quebrar um "mental set"(6)

(6) Consiste numa estrutura mental pela qual o pensamento de uma pessoa, num dado momento, "will follow the lines on which he starts off"» (Eden, Jones \& Sims, 1979: 91). De facto, 
a que os indivíduos eventualmente, estariam sujeitos no momento da primeira recolha de dados (Eden, Jones \& Sims, 1979). Assim, realizada com base no mapa cognitivo elaborado, constituiu uma oportunidade não só para a validação pelo entrevistado, do mapa elaborado - validação feita com base no reconhecimento e na aceitação quer dos conceitos como das relações estabelecidas entre eles representados no mapa - como também uma oportunidade para aprofundar a exploração de conceitos significativos do sistema de crenças do indivíduo, nomeadamente os seus opostos psicológicos, e as suas causas e explicações.

Apesar de ter revestido características diferentes de entrevistado para entrevistado, tendo em atenção as especificidades dos mapas de cada um, a entrevista de validação consistiu basicamente em dois momentos: o da exploração de opostos de conceitos e um segundo momento, o do desenvolvimento ou aprofundamento de ideias. No primeiro momento, consideraram-se os conceitos constituídos apenas por um pólo e explorou-se para cada um o seu oposto perguntando aos indivíduos: "Qual é na sua opinião, a alternativa (satisfatória ou negativa conforme o indivíduo tivesse indicado uma ou outra) para esta circunstância? É importante que nos dê a suo opinião e não o ponto de vista "oficial" da Organização"; no segundo momento, estimulava-se o desenvolvimento de ideias através de questões do tipo: "Porque é que isto o preocupa?" ou "Porque é que está preocupado com isto?" - exploração das consequências - e, "Que razões encontra que expliquem tal?" ou "Porque é que isto é assim?" - exploração das causas -. Em qualquer um destes momentos foi dado ao entrevistado o tempo necessário para ir até ao "fundo da questão", tendo todo este processo de exploração sido mantido até o indivíduo não ser capaz de dizer mais nada sobre o assunto.

\section{Instrumento de análise}

Para análise dos dados relativos ao conhecimento ou às estruturas de conhecimento que os responsáveis bancários sustentam sobre "organização", utilizámos a técnica de Graphics COPE - "Graphics Cognitive Policy Evalua-

\footnotetext{
segundo os autores, se recolhermos dados em momentos diferentes teremos mais hipóteses de abarcarmos melhor todas as crenças sustentadas pelo indivíduo sobre a temática em estudo isto porque, dadas as nossas limitações cognitivas, não somos capazes de num dado momento, nos lembrarmos de todas as causas elou consequências que acreditamos estarem relacionadas com um dado acontecimento.
} 
tion" - técnica informatizada de mapeamento cognitivo desenvolvida com base na Teoria de Constructos Pessoais de Kelly (1963) por Eden e colaboradores na Universidade de Strathclyde (Escócia).

A Teoria de Constructos Pessoais desenvolvida por Kelly no domínio da clínica, enfatiza "o "Homem como um cientista" que continuamente se esforça por fazer sentido do seu mundo (Eden, Williams \& Smithin, 1986: 235) tendo em vista a acção no e sobre o mundo (Eden, 1988a: 4) com o intuito de o controlar. Assentando no pressuposto base( $(7)$ de que «Os processos de uma pessoa são psicologicamente orientados pela forma como ela antecipa os acontecimentos» (Kelly, 1963: 46), esta teoria defende que os indivíduos desenvolvem a partir das replicaçōes desses acontecimentos, sistemas de construção idiossincráticos ou pessoais (corolários da individualidade e da construção) constituídos por constructos dicotómicos (corolário da dicotomia) que estabelecem entre si relaçōes ordinais (corolário da Organização). O seu conceito chave é exactamente o de "constructo", que o autor define como «formas de construção do mundo» ou "padrões que o indivíduo cria e tenta depois adaptar às realidades de que é composto o mundo» (Kelly, 1963:9) e com as quais ele se confronta diariamente(8).

É com base nesta teoria que Eden desenvolve a técnica do GCOPE com o objectivo de captar um "sistema de constructos pessoais" (Eden, Jones \& Sims, 1979; Eden, 1988b). Para o autor, o mapeamento cognitivo constrói-se sobre três asserções chave daquela teoria: primeiro, o Homem atribui sentido ao seu mundo através do contraste e da semelhança, isto é, o significado no contexto da acção, deriva do relativismo; segundo, o Homem procura explicar o seu mundo - porque é que é como é, o que é que o faz ser assim; e, terceiro, o Homem procura compreender a significância do seu mundo organizando os conceitos hierarquicamente de tal forma que alguns conceitos estão subordinados a outros (Eden, 1988a: 3-4).

A forma como procedemos constituiu basicamente um método heurístico 18 de leitura do material recolhido e um método de produção de hipóteses sobre o conhecimento que aqueles responsáveis possuem sobre «organização».

(7) A Teona dos Constructos Pessoais tal como foi proposta por Kelly (1963), define-se através de doze pressupostos, um pressuposto fundamental e, onze corolários deste.

(8) Assim definido, este conceito equivale ao de "estrutura de conhecimento", o conceito chave da abordagem "top-down" ou theory driven de processamento de informação como dissemos anteriormente. 
A técnica foi utilizada de acordo com a proposta original dos seus autores tendo nós no entanto, procedido com base numa análise de conteúdo, à categorização dos conceitos de cada modelo analisado. Para tal, utilizámos como referente a diferenciação que Duncan (1977, citado por Duncan \& Weiss, 1979) fez de meio organizacional diferenciando os conceitos de acordo com o seu conteúdo, em dois grandes grupos, (a) conceitos relativos ao meio interno e, (b) conceitos relativos ao meio externo da Organização. No primeiro grupo, considerámos os conceitos relativos aos trabalhadores/pessoal, à organizoção e, à Empresa em geral; no segundo grupo, considerámos conceitos relativos aos clientes e à concorréncia. Foram utilizados os seguintes critérios para a categorização dos diferentes conceitos:

1) Os conceitos cujo conteúdo nos remete para alguma característica intrínseca das diferentes entidades consideradas (pessoas, organização, empresa, clientes e concorrentes), serão categorizados como sendo desse domínio de conceitos.

Englobamos neste caso, conceitos do tipo maior satisfação do trabalhador (conceito pessoal); aumenta a qualidade do serviço (conceito organização); mais lucros para o banco (conceito empresa); satisfação completa do cliente (conceito cliente); maior agressividade da concorrencia (conceito concorrentes);

2) Os conceitos expressos através de um sujeito, de uma acção e de um beneficiário dessa acção, são categorizados de acordo com o sujeito. uma vez que é ele o autor da acção destacada.

São conceitos deste tipo por ex, o trobalhador resolve o problema ao cliente (conceito pessoal); o banco conhece o que a concorréncia está a fazer (conceito empresa); o cliente fala bem do banco (conceito clientes).

Outros conceitos houve que, por não ter sido possivel categorizá-los através das duas formas referidas, foram categorizados de acordo com o próprio conteúdo do seu texto e com o sentido que o seu autor the atribuiu. Assim, foram considerados no domínio pessoal/trabalhadores conceitos que embora relativos aos trabalhadores não se reportam a características intrínsecas destes, por ex, conceitos relativos à variação da quantidade de trabalhadores, às variações nas taxas de absentismo; no domínio organização, foram consideradas características organizacionais tais como aspectos relativos ao serviço, ao atendimento, à tecnologia das unidades funcionais. A rotação de 
pessoal, o enriquecimento do trabalho, foram também e porque se referem a medidas organizativas, considerados como conceitos organização.

Ainda que o GCOPE não proponha este tipo de análise optámos por a realizar, porque do ponto de vista da análise nos pareceu ser enriquecedor e facilitador da sua interpretação. Só desta forma de facto, seria possível a interessante comparação dos diferentes conceitos considerados por cada entrevistado em cada um destes domínios e, também, estar atento aos novos domínios de conceitos criados em cada caso. Para tal, e apesar da consideração prévia dos domínios de conceitos anteriormente definidos, mantivemo-nos atentos na análise de cada caso, ao aparecimento e notação de outro tipo de conceitos.

\section{RESULTADOS E SUA DISCUSSĀO}

$\mathrm{Na}$ impossibilidade de apresentarmos aqui as características específicas de cada um dos modelos, optámos por elaborar uma síntese comparativa dos cinco modelos analisados. Consideraremos para isso dois níveis distintos embora complementares, o primeiro, o das características extrínsecas dos modelos e, o segundo, o do seu conteúdo e estrutura, ou seja, o nível de análise que nos permite de facto, identificar e compreender o conhecimento que os responsáveis bancários entrevistados possuem sobre organização.

Os resultados mostraram que na essência, os mapas cognitivos elaborados não se diferenciavam significativamente nem quanto às suas característicos extrínsecos nem quanto ao seu conteúdo e estrutura.

As principais características extrínsecas, a partir das quais poderemos concluir do grau de complexidade cognitiva dos modelos analisados, encontram-se sintetizadas no Quadro I.

Relativamente ao número de conceitos e de relaçōes identificados em cada um dos modelos, verificamos haver uma relativa homogeneidade, que é maior para o número de conceitos do que a que se verifica para o número de relações. A diferença entrero número de conceitos e o número de relações só se veio a tornar relativamente diferenciadora no caso $b$ que como podemos verificar, apresenta o maior valor para a razão número de relações vs. número de conceitos, indicadora de maior complexidade cognitiva deste mapa. 
QUADRO I

PRINCIPAIS CARACTERISTICAS ESTRUTURAIS DOS MAPAS COGNITIVOS INDIVIDUAIS

Casos

\begin{tabular}{|c|c|c|c|c|c|}
\hline \multirow[b]{2}{*}{ Características } & \multicolumn{2}{|c|}{ Gestores } & \multicolumn{3}{|c|}{ Técnicos da DOI } \\
\hline & $a$ & $b$ & $c$ & $d$ & e \\
\hline N. ${ }^{\circ}$ conceitos & 73 & 68 & 65 & 62 & 71 \\
\hline N. relações & 102 & 106 & 93 & 84 & 90 \\
\hline N. ${ }^{\circ}$ conceitos $/ n .^{\circ}$ relações & 1.4 & 1.6 & 1.4 & 1.35 & 1.27 \\
\hline N. ${ }^{\circ}$ conceitos "topo" & 4 & 2 & 7 & 3 & 7 \\
\hline N. ${ }^{\circ}$ conceitos "base" & 12 & 10 & 12 & 9 & 14 \\
\hline N. ${ }^{\circ}$ clusters & 3 & 2 & 3 & 3 & 3 \\
\hline N..$^{\circ}$ loops & 5 & 19 & 4 & 6 & 8 \\
\hline $\mathrm{N} .^{\circ}$ conceitos em loops & $18(25 \%)$ & $19(28 \%)$ & $7(11 \%)$ & $11(18 \%)$ & $19(27 \%)$ \\
\hline
\end{tabular}

Em todos os modelos o número de conceitos "topo" é menor do que o número de conceitos "base"(9) identificados, o que nos diz de imediato que relativamente à temática em estudo, os entrevistados consideram um conjunto relativamente limitado de resultados desejáveis ou objectivos a alcançar - nalguns casos como por ex., nos casos $a, b$ e $d$. pode-se falar mesmo em fixação num conjunto restrito (dois, três, quatro) de resultados tidos como desejáveis -; e, simultaneamente consideram um leque mais diversificado de opções potenciais que os sujeitos interpretam como disponiveis para seleccionar a ou as acções que permitirão a concretização das "questões chave", situadas hierarquicamente, acima daquelas.

Dois casos no entanto, merecem destaque, o caso $c$ e o caso e, ambos com sete conceitos "topo". o que evidencia relativamente aos sujeitos a que reportam, que possuem uma elaboração um pouco mais diversificada do que

(9) Os conceitos "topo" ou "influencıados" são concertos aos quals o entrevistado não atribui consequências, situando-se por isso, no topo de uma ou mais cadeias argumentativas; os con. ceitos "base" ou "influenciantes" são pelo contráno, conceitos aos quais o individuo não atnbui explicaçōes ou causas, ou seja, sāo concertos que inıciam uma ou mas cadeias de argumentação 
os outros três entrevistados, no que concerne aos objectivos organizacionais que consideram desejáveis alcançar.

Quanto ao número de agrupamentos ou clusters constituídos, verificámos que, exceptuando o caso $b$, onde foram identificados apenas dois, todos os modelos foram divididos em três clusters. Como a forma de análise de agrupamentos ou clusters que é realizada pelo GCOPE, segue os princípios do "agrupamento por ligação simples"(10), o seu menor número num modelo ou mapa é também indiciador de maior complexidade cognitiva dos mapas. Assim sendo, podemos continuar a concluir da maior complexidade cognitiva do modelo relativo ao caso $b$.

Constituindo os loops ou círculos discursivos afirmações acerca da causa de dinâmicas contínuas no mundo "natural" ou, reflectindo alternativamente, uma "teoria - em - uso" (Argyris \& Schön, 1974, 1978) do cliente para controlar o seu mundo (Eden, Jones \& Sims, 1979), implicam a existência possível de consideração dinâmica na cognição do indivíduo cujo discurso está a ser analisado e constituem uma pista importante para análise da complexidade dos mapas elaborados.

Relativamente ao número de loops encontrados nos cinco modelos, destacamos também aqui o caso $b$, aquele onde foram identificados o maior número de loops, nomeadamente dezanove. Considerando entretanto, o número de conceitos diferentes que integram os loops e, a sua representatividade no número total de conceitos do modelo, podemos concluir ainda que embora em menor número, os loops identificados no caso $a$ e no caso e, porque constituídos por $25 \%$ e por $27 \%$ respectivamente, do número total de conceitos dos respectivos modelos, representam um sinal/indício de alguma complexidade cognitiva dos mesmos.

No entanto, e numa globalidade, podemos concluir que em termos de complexidade cognitiva, estes cinco modelos elaborados com base em entrevistas com um guião semelhante, sobre o conhecimento que responsáveis

(10) Olhando para cada constructo e para o seu contexto imediato de constructos determina uma "similarity rating" (conhecido matematicamente como o coeficiente de jacquard) os agrupamentos são formados gradualmente colocando constructos relativamente semelhantes no mesmo grupo até ter sido alcançado um nível definido de dissemelhança. A intenção é tentar formar agrupamentos em que os constructos que os constituem estejam muito relacionados uns com os outros e 0 n. ${ }^{\circ}$ de relaçōes (ou pontes) com outros agrupamentos esteja minimizado. 
bancários possuem sobre organização, não são muito diferentes apresentando numa generalidade, uma baixa complexidade cognitiva.

\section{Características de conteúdo e estrutura dos modelos}

Relativamente aos conceitos considerados por cada entrevistado não há numa generalidade, relativamente aos domínios encontrados e à quantidade de conceitos em cada um deles, também diferenças significativas de caso para caso - ver Quadro 2.

QUADRO 2

QUANTIDADE DE CONCEITOS POR DOMINIO CONSIDERADO, REFERIDOS PELOS CINCO ENTREVISTADOS NO TOTAL

Casos

\begin{tabular}{|c|c|c|c|c|c|c|}
\hline \multirow[b]{2}{*}{ Domínios } & \multicolumn{2}{|c|}{ Gestores } & \multicolumn{3}{|c|}{ Técnicos da DOI } & \multirow[b]{2}{*}{$\Sigma$} \\
\hline & $a$ & $b$ & c & $d$ & e & \\
\hline Organização & 24 & 20 & 26 & 24 & 33 & 127 \\
\hline Pessoal & 27 & 31 & 18 & 17 & 21 & 114 \\
\hline Empresa & 12 & 9 & 14 & 15 & 9 & 59 \\
\hline Sub-Total, & 63 & 60 & 58 & 56 & 63 & 300 \\
\hline Clientes & 3 & 6 & 2 & 4 & 6 & 21 \\
\hline Concorrência & 3 & 2 & 3 & 1 & 1 & 10 \\
\hline Político-económica & 4 & - & 2 & I & 1 & 8 \\
\hline Sub-Total 2 & 10 & 8 & 7 & 6 & 8 & 39 \\
\hline
\end{tabular}

Verifica-se uma supremacia de conceitos do meio interno relativamente aos do meio externo nos cinco casos, representando os primeiros de $86 \%$ (caso a) a $90 \%$ (caso d) do total de conceitos referidos por cada entrevistado. Destes, os conceitos relativos à organização, predominam nos três casos relativos aos técnicos da $\mathrm{DOl}$ e, nos casos $a$ e $b$, os relativos aos dois gestores, o predomínio é dos conceitos relativos ao pessoal. Admitindo que a entrevista foi conduzida de forma idêntica, isto é, independentemente da função desempenhada por cada entrevistado na Organização de pertença, este facto parece-nos significativo do ponto de vista da análise. 
discursos relativamente aos conceitos organização que cada um deles considera mais pregnante no tema em análise. $O$ que não se verifica relativamente aos aspectos relativos à política - económica, ao pessoal, à empresa e aos clientes, onde há um conjunto preciso e mais restrito de conceitos que elaboram ou ajudam a elaborar o discurso da maioria dos entrevistados sobre o tema em estudo.

A análise efectuada permitiu-nos verificar que $58 \%$ dos conceitos são partilhados pela maioria dos elementos do banco $\mathrm{A}$; enquanto que se verifica uma partilha de $42 \%$ dos conceitos entre os dois entrevistados do banco $\mathrm{C}$ (Quadro 3).

QUADRO 3

QUANTIDADE DE CONCEITOS PARTILHADOS PELOS MEMBROS DA MESMA ORGANIZAÇÃO POR DOMINIO A QUE PERTENCEM

\begin{tabular}{|c|c|c|c|c|c|c|c|c|c|}
\cline { 2 - 10 } \multicolumn{1}{c|}{} & \multicolumn{4}{c|}{ Acordo total } & \multicolumn{4}{c|}{ Acordo parcial } & \multicolumn{1}{c|}{} \\
\hline Bancon $_{\text {Concitos }}$ & Emp. & Org. & Pes. & M Ext & Emp. & Org. & Pes. & M Ext & $\Sigma$ \\
\hline$A(N=3)$ & 3 & 8 & 3 & 1 & 4 & 6 & 6 & 5 & 38 \\
\hline$C(N=2)$ & 5 & 9 & 10 & 4 & & & & & 28 \\
\hline
\end{tabular}

Tais resultados permitem-nos afirmar que em geral, entre os membros do mesmo banco, isto é, entre os que desempenham papéis no mesmo processo social se verifica uma partilha de significados ou que eles possuem uma construção semelhante da experiência em orgonizoção (Kelly, 1963). Facto que nos permite supor a existência de uma estrutura linguística comum ou mapa colectivo, aos elementos de uma mesma organização relativamente à temática em estudo(12).

Especificação da estrutura dos modelos elaborados

Com base no conteúdo dos modelos individuais e tomando como referentes especificamente os seus conceitos chave. podemos concluir que numa

(11) Só é válido para o banco $A$ onde entrevistámos três dos elementos que participaram na restruturação dos balcões.

(12) Estrutura colectiva de conhecimento que fol por nós explorada posteriormente num outro estudo empínico. 
discursos relativamente aos conceitos organização que cada um deles considera mais pregnante no tema em análise. $O$ que não se verifica relativamente aos aspectos relativos à político - económica, ao pessoal, à empresa e aos clientes, onde há um conjunto preciso e mais restrito de conceitos que elaboram ou ajudam a elaborar o discurso da maioria dos entrevistados sobre o tema em estudo.

A análise efectuada permitiu-nos verificar que $58 \%$ dos conceitos são partilhados pela maioria dos elementos do banco $\mathrm{A}$; enquanto que se verifica uma partilha de $42 \%$ dos conceitos entre os dois entrevistados do banco C (Quadro 3).

QUADRO 3

QUANTIDADE DE CONCEITOS PARTILHADOS PELOS MEMBROS DA MESMA ORGANIZAÇĀO POR DOMINIO A QUE PERTENCEM

\begin{tabular}{|c|c|c|c|c|c|c|c|c|c|}
\cline { 2 - 10 } \multicolumn{1}{c|}{} & \multicolumn{4}{c|}{ Acordo total } & \multicolumn{4}{c|}{ Acordo parcial (11) } & \multicolumn{1}{c|}{} \\
\hline Banconceitos & Emp. & Org. & Pes. & M Ext & Emp. & Org. & Pes. & M Ext & $\Sigma$ \\
\hline A (N=3) & 3 & 8 & 3 & 1 & 4 & 6 & 6 & 5 & 38 \\
\hline$C(N=2)$ & 5 & 9 & 10 & 4 & & & & & 28 \\
\hline
\end{tabular}

Tais resultados permitem-nos afirmar que em geral, entre os membros do mesmo banco, isto é, entre os que desempenham papéis no mesmo processo social se verifica uma partilha de significados ou que eles possuem uma construção semelhante da experiência em organização (Kelly, 1963). Facto que nos permite supor a existência de uma estrutura linguística comum ou mapa colectivo, aos elementos de uma mesma organização relativamente à temática em estudo(12).

Especificação da estrutura dos modelos elaborados

Com base no conteúdo dos modelos individuais e tomando como referentes especificamente os seus conceitos chave, podemos concluir que numa

(11) Só é válido para o banco $A$ onde entrevistámos três dos elementos que participaram na restruturação dos baicões.

(12) Estrutura colectiva de conhecimento que foi por nós explorada posteriormente num outro estudo empinico. 
globalidade os entrevistados partilham dos pressupostos clássicos ou convencionais de organização tal como foram sistematizados por diversos autores (McGregor, 1960; Morgan \& Ramirez, 1983; Morgan, 1986, 1989).

Esta imagem transparece quer dos princípios organizativos defendidos como também, das teorias que os entrevistados sustentam sobre o trabalhador e sobre os motivadores para o trabalho. No entanto, no que concerne à perspectiva do meio externo sustentada e evidenciada nos modelos individuais esta é em contrapartida, menos clássica do que a habitual.

Assim, ao nivel organizativo propriamente dito, verificámos que o conhecimento dos entrevistados - excepção feita para o caso $a-$ não possuem em geral alternativas às propostas mais clássicas de organização já que os conceitos mais importantes deste agrupamento são a redução das cargas administrativas e a consequente racionalização e simplificação dos circuitos, a eliminação de postos de trabalho, a diminuição dos custos de funcionamento, aspectos para os quais muito contribui a opção pela introdução de tecnologias de informação, conceito também fulcral no conhecimento elicitado e que vai estar na origem daquilo que os entrevistados consideram ser uma boa organização. Apesar de serem consideradas algumas medidas de restruturação ao nivel individual dos postos de trabalho, como a rotaçāo dos trabalhadores e 0 alargamento dos postos de trabalho, para aumentar a motivação dos trabalhadores, estas permitindo a polivalência do trabalhador e esta, a redução do número de trabalhadores, constituem antes respostas à necessidade da Organização de reduzir custos, aspecto que em último caso, vai permitir o aumento dos lucros, o resultado mais desejado - conceito "topo" mais elaborado para a maioria dos entrevistados.

Relativamente à imagem transmitida do trabalhador evidencia-se no discurso dos entrevistados uma clara separação entre a imagem que possuem do trabalhador mais jovem e a que possuem do trabalhador mais velho. Assim, esta imagem é bastante mais negativa relativamente ao trabalhador mais velho do que em relação ao trabalhador mais jovem.

Os trabalhadores mais velhos são descritos como tendo um desinteresse inerente pelo trabalho, pouca ambição, são vistos como pessoas que desejam evitar a responsabilidade, sem aptidão para lidar com tecnologias nem preparação para contactar com o público e vender os produtos bancários; sem formação informática e sem motivação para aprenderem este novo domínio facto decididamente limitativo da integração destes trabalhadores, quando se 
considera como é o caso, que a informatização desempenha papel crucial na racionalização dos procedimentos e por isso, no bom funcionamento do serviço - e sem capacidade de se tornar polivalente porque rotinado em determinado serviço ao longo dos anos. Esta imagem negativa do trabalhador mais velho é tanto mais forte quanto os entrevistados não lhes reconhecem qualquer capacidade de aprendizagem.

São os trabalhadores mais novos que na perspectiva dos entrevistados se adequam melhor às exigências actuais do trabalho: possuem aptidão (inata) para lidar com tecnologias, estão também à partida mais bem preparados para assumirem uma atitude activa de venda que implica contacto com o público e alguma capacidade de persuasão.

Como a redução dos trabalhadores desempenha um papel também preponderante nas teorias sustentadas pelos entrevistados, e a sua formação não aparece como um meio de desenvolvimento dos seus recursos, podemos concluir que estamos perante uma perspectiva quantitativa dos recursos humanos vistos como "custos a minimizar", a perspectiva clássica, e não como "recursos a optimizar" ou desenvolver (Besseyre Des Horts, 1988).

Quanto aos pressupostos sobre os motivadores do comportamento do pessoal, verificamos por um lado, que a motivação dos trabalhadores é entendida como um dos elementos chave para o alcance dos principais objectivos do banco. A motivação dos trabalhadores é ou deve ser, segundo a teorização dos entrevistados, promovida de várias formas que não só através de incentivos e/ou recompensas económicas, recompensas extrínsecas ou instrumentais (Katz \& Kahn, 1987), as tradicionalmente exploradas e utilizadas pela Gestão. No entanto, apesar da referência a motivadores intrínsecos como por ex., o sentimento de maior utilidade e de realização no trabalho, e também aspectos organizativos, como o trabalho menos rotineiro e a existência de postos de trabalho com várias tarefas, verifica-se que sempre que os incentivos e/ou recompensas económicas são explicitamente considerados pelos entrevistados eles assumem papel preponderante como motivador do comportamento no trabalho estando sempre associados a lógicas circulares discursivas.

Podemos concluir que em geral, a imagem transmitida do trabalhador em muito se identifica à do "trabalhador máquina" que para que funcione bem é necessário que seja novo e suficiente que tenha todas as "peças" componentes em perfeitas condições. 
A única "nota" aparentemente discordante do cenário que até agora traçámos é a consideração e sobretudo a importância que a maioria dos indivíduos - excepção para o caso e - atribui aos conceitos relativos ao meio externo, postura pouco típica de quem partilha os pressupostos das teorias de organização mais convencionais. De facto, a maioria dos entrevistados não só não ignora a influência do meio externo, como é típico nas teorias mais convencionais de organização, como está manifestamente consciente da importância que algumas das suas características têm sobre as Organizações. Este tipo de conceitos apesar da sua pouca frequência nos mapas cognitivos elaborados, desempenham assim um papel chave na teorização que cada um dos indivíduos faz sobre organização constituindo na verdade, a sua base ou - suporte alicércico dos mapas ou modelos elaborados. Assim, parece claro que a adesão de Portugal à CEE ao provocar a abertura do mercado desencadeou uma concorrência desenfreada e agressiva à qual os bancos têm necessidade de dar resposta no sentido de continuar a cativar clientes, fidelizando-os ao banco e continuando desta forma, a garantir a prossecução dos seus objectivos económico - financeiros. É assim, devido fundamentalmente ao factor concorréncia, que o meio externo deixa de ser lido como simples e acolhedor para passar a ser visto como dinâmico e hostil (Mintzberg, 1982. 1990), o que vem desencadear a necessidade de mudanças ao nível interno da organização de forma a garantir a sobrevivência organizacional.

Os clientes passam a ser vistos como as verdadeiras "jóias da coroa" que é preciso conservar e, se possivel, fazer aumentar, a qualquer custo. É por eles que todas as mudanças organizacionais são concebidas de forma a que o banco continue a prosseguir o seu principal objectivo que é o de ter mais lucros. Por este motivo, uma postura passiva perante o cliente, a tradicionalmente adoptada, deixa de servir sendo preciso substituíla por uma atitude activa e mais agressiva de contacto com o cliente e de venda de produtos.

À laia de conclusão, podemos dizer que o conhecimento que os entrevistados manifestam sobre organização, reflecte basicamente os pressupostos básicos das teorias racionais de sistema aberto (Scott, 1987). Ou seja, embora considerem as relações que as Organizações estabelecem com o meio, têm subjacente o pressuposto de que estas se comportam como sistemas racionais. 


\section{CONCLUSÕES E REFLEXŌES FINAIS}

A finalizar gostariamos de reflectir sobre duas questões intimamente relacionadas e que ressaltam da interpretação que fizemos dos resultados encontrados: a da necessidade de mudança das formas de perspectivar quer os contextos de trabalho como os recursos humanos.

Verificámos que a lógica que continua a fazer funcionar as Organizações e os que nelas detêm poder, é a lógica das teorias clássicas da organização que desenvolveram princípios de funcionamento organizacional muito idênticos aos da máquina, como se os únicos inputs organizacionais fossem os produtivos ignorando quase por completo os inputs de manutenção (Katz \& Kahn, 1987). Numa generalidade, o objectivo primário destas Organizações é o de aumentar os lucros da empresa, facto que por si só, não é estranho pois afinal, estamos a falar de Organizações com fins lucrativos, isto é, Organizações cujo firm último para que foram concebidas é exactamente o de obter lucros. O que chama a atenção é sim, a perspectiva sobre os recursos humanos e sobre as Organizações enquanto contextos de trabalho, que transparece em todos os casos. A imagem que transparece é a de Organizaçōes máquinas (Morgan, 1980, 1983; 1986; 1989) em que todas as suas componentes e recursos incluindo os humanos, são vistos como peças que devem estar bem oleadas para que a máquina funcione bem e produza o desejável. Portanto, os contextos de trabalho continuam a ser encarados como contextos aos quais os recursos humanos se devem adaptar o melhor possivel tendo em vista exclusivamente os objectivos organizacionais. Vivemos assim, na era do domínio organizacional e laboral, em que ninguém é alguém fora duma qualquer Organização e dentro delas perde-se muitas das vezes, a identidade pessoal. Os objectivos a cumprir são os da Organização que a maior parte das vezes, por processos muito bem montados de socialização e endoutrinamento (Mintzberg, 1982, 1990) nos fazem sentir serem os nossos, isto porque nem sequer nos dão tempo a saber quais eles são. De facto, não vendo satis-

feitas as suas necessidades básicas de segurança, o Homem acaba por aderir a este sistema, não the restando outra alternativa a não ser resistir ao seu "engolimento" pela Organização e fazer apenas uma inclusão parcial (Katz \& Kahn, 1987) nela.

Não é na nossa opinião, nem inevitável nem desejável que assim seja. Não é inevitável porque existem formas organizativas alternativas que pare- 
cem não fazer parte do conhecimento ou das teorias sustentadas pelos entrevistados. Não é desejável, porque tais formas organizativas, têm mostrado não corresponder nem às aspirações nem aos níveis de escolarização actuais dos trabalhadores - de facto, as aspirações e os níveis de escolarização superiores devem traduzir-se no local de trabalho por exigências de individualidade, autonomia, poder partilhado, carreiras, recompensas apropriadas, sentido/significado e reconhecimento, etc., aspectos ausentes das formas tradicionais de organização.

Julgamos que uma das razões para que os responsáveis não se sintam motivados ou incentivados a mudar tais pressupostos poderá ter a ver com o facto do mercado de trabalho possuir excedente de mão de obra, facto que promove a manutenção de tais pressupostos(13). Assim, embora o que melhor caracteriza o ambiente externo da Organização seja a mudança a diversos níveis, nomeadamente ao nível social, político, tecnológico, o que tem determinado grandemente a lógica de emprego é exactamente, a existência de mão de obra excedente. Lógica que no início do século, criou as condições ideais para o aparecimento e florescimento de modelos de organização do tipo taylorista, com a diferença de que o que na altura predominava era uma mão de obra sem qualquer qualificação ao contrário exactamente do que acontece hoje!

No fundo, o problema subjacente a esta questão é o de saber como desenhar as Organizaçōes e desenvolver os indivíduos de modo a maximizar a eficácia de cada um. Como integrar os objectivos de uma Organização produtiva com as necessidades de um empregado adulto? Julgamos que a prossecução dos objectivos organizacionais não é em si, incompatível com a prossecução dos objectivos individuais, tudo depende da perspectiva integrada que se tem quer do papel dos contextos de trabalho como dos recursos humanos: deverão os primeiros promover o desenvolvimento humano ou deverão limitar-se a confirmar e replicar as práticas discriminatórias sobejamente conhecidas do meio social e escolar?

30 Estando a sociedade estruturada da forma como está, em Organizações, e assentando a economia dos países no trabalho desenvolvido no conjunto

(13) Veja-se por ex., o facto de que actualmente neste tipo de Organizaçōes, o recrutamento e a selecção serem frequentemente fertos acima das necessidades dos postos - os licenciados por ex., são aliciados para funçōes que posteriormente se mostram aquém das suas ambições e qualificações. 
dessas Organizações, todo aquele que fica fora delas, voluntariamente ou não, é automaticamente excluído também da sociedade e das suas normas - o que terá consequências não só ao nível individual, organizacional como também social.

Assim sendo, a nossa perspectiva é a de que se o Psicólogo intervém em outros contextos nomeadamente familiares e educativos tentando promover o desenvolvimento pessoal no interior dos mesmos - isto é, não é objectivo da sua intervenção retirar o indivíduo destes contextos de forma a promover o seu desenvolvimento/aprendizagem - então também é possível e acrescentaríamos grandemente desejável atendendo ao que dissemos anteriormente sobre as consequências sociais da exclusão, intervir nos contextos laborais com o mesmo objectivo, o de que eles promovam o desenvolvimento humano no seu interior. Além disso, se atendermos ao facto de que desde o momento que alguém inicie a sua vida profissional, estes contextos tomam-se mais invasores da vida individual do que qualquer um dos outros - veja-se que se passa o maior número de horas acordado no seu interior - podemos facilmente perceber a importância e a urgência na sua intervenção.

Tendo em atenção o que reflectimos até aqui, defendemos a necessidade de perspectivar os contextos de trabalho como contextos que devem potencializar e promover o desenvolvimento e crescimento humanos, ou seja, a necessidade de integrar os objectivos de uma Organização produtiva com as necessidades dos seus trabalhadores; nesta medida, estes não deverão ser entendidos como custos a minimizar - perspectiva tradicionalista de gestão dos Recursos Humanos - mas antes como meios a desenvolver (Besseyre Des Horts, 1988).

Sendo o processo de restruturação dos balcões um processo colectivo, parece-nos que a exploração da existência de "estruturas colectivas de conhecimento" sobre organização numa dada instituição de crédito e a sua tradução em opções organizativas concretas, deverão ser duas das vias futuras de investigação nesta área.

Posteriormente, seria importante a concretização de um ou vários estudos aprofundados sobre as origens das estruturas de conhecimento, que nos permitissem explorar qual o papel da formação académica e profissional dos gestores no desenvolvimento e sedimentação dos registos discursivos evidenciados neste estudo. Considerando que há uma relação entre a mudança das estruturas organizacionais e a mudança das estruturas cognitivas como diver- 
sos autores têm evidenciado (Bartunek, 1984; Isabella, 1990), torna-se fundamental conhecer as origens das estruturas de conhecimento identificadas de forma a planear-se uma intervenção que venha a permitir a sua alteração ou substituição. Só desta forma será possível esperar mudanças reais nas formas tradicionais de organização.

\section{REFERENCIAS}

ABELSON. R. P. \& BLACK, J. B. (1986). Introduction. In J.A. Galambos, R. P. Abelson \& J. B. Black (Eds.). Knowledges structures (Cap. 1, pp. 1 - 18). Hillsdale, N].: Lawrence Erlbaum Associates. ACKERMAN, F \& SWEENEY, M. (1995). Graphics Cope: User guide. Glasgow. University of Strathclyde.

ARGYRIS, C. \& SCHÖN, D. A. (1974). Theory in practice. Increosing professional effectiveness. San Francisco, CA: Jossey-Bass Publishers.

ARGYRIS, C. \& SCHÖN, D. A. (1978). Organizational learning: A theory of action perspective. Reading, Massachusetts: Addison-Wesley Publishing Company.

ASTLEY,W. G. \& VAN DE VEN. A. H. (1983). Central perspectives and debates in organization theory. Administrative Science Quarterly, 28, 245-273.

BARTUNEK, J. (1984). Changing interpretive schemes and organizational restructuring: The example of a Religious Order, Administrative Science Quarterly, 29, 355-372.

BENSON. J. K. (1977). Organizations: A dialectical view. Administrotive Science Quarterly, 22, 1-21. BESSEYRE DES HORTS, C. H. (1988). Vers une gestion strotégique des ressources humaines. Paris: Les Éditions d' Organization.

BURRELL G. \& MORGAN, G. (1979). Sociological Paradigms and Organizotional Analysis. Londres: Heinemann Educational Books Ltd..

COSSETTE. P. (1989). Les schèmes d' interprétation idiosyncratiques de propriétaires-dirigeants de PME: Une Étude de Cortographie Cognitive. Thèse de Doctorat Inédit, Québec: Université Laval.

COSSETTE, P. (1994). Cortes cognitives et orgonisotions. Québec: Les Presses de Lúniversité Laval.

COSSETTE, P. (1994). Les Cartes Cognitives au service de l'étude des Organisations. In Pierre Cossette (Direction). Cartes cognitives et organisations. Québec: Les Presses de Lúniversité Laval.

32 CROZIER, M. \& FRIEDBERG, E. (1977). L' acteur et le système. Les contraintes de l' action collective. Paris: Éditions du Seuil.

DUNCAN, R. B. \& WEISS, A. (1979). Organizational learning: Implications for organizational design. In B. Staw (Ed.). Research in Organizational Behovior (Vol. I. pp. 75-123). Greenwich, Connecticut: JAl Press.

EDEN. C. (1988a). Cognitive Mapping. European fournal of Operotional Research, 36, 1-13.

EDEN, C. (1988b). COPE: Reference Manual. Glasgow, UK: University of Strathclyde, Department of Management Science. 
EDEN, C., JONES, S. \& SIMS, D. (1979). Thinking in organizations. London: The Macmillan Press Ltd. EDEN, C., JONES, S. \& SIMS, D. (1983). Messing about in problems. An informal structured approach to their identification and management. Oxford: Pergamon Press.

EDEN. C.,WILLIAMS, H. \& SMITHIN, T. (1986). Synthetic wisdom:The design of a mixed-mode modelling system for organizational decision making. Journal of the Operational Research Society, 37 (3), $233-241$.

ERDENER C. B. \& DUNN, C. P. (1990). Content Analysis. In Hiuff, A. S. (Ed.). Mopping Strategic Thought (Cap. II.pp. 291-300). West Sussex John Wiley \& Sons Ltd.

GRAWITZ, M. (1986). Méthodes des sciences sociales (7 Ed.). Paris: Dalloz. Livro II, Cap. N, pp. 490-493: Livro III, Titre I, Cap.ll, pp. 670-716.

HALL, R. H. (1987). Organizations: Structures, processes and outcomes (4th Ed.). Englewood Cliffs, Nj: Prentice-Hall International, Inc..

HOSKING, D.-M. \& MORLEY, I. E. (1991). A Social psychology of organizing. People, processes and contexts. London: Harvester Wheatsheaf.

HUFF, A. S. \& FLETCHER, K. E. (1990). Conclusions: Key mapping decisions. In Huff, A. S. (Ed.). Mapping Strotegic Thought (Cap. 13, pp. 311-325). West Sussex: John Wiley \& Sons Ltd.

ISABELLA. L.A. (1990). Evolving interpretations as a change unfolds: How managers construe key organizational events. Acodemy of Management Journol, 33 (1). 7-4I.

IONES. M. (1994). Graphics Cope: Reference Manual. Glasgow: University of Strathclyde.

JORDĀO, F. (1988). A reconcepção dos postos de trabalho e as novas tecnologias: Porto: FPCE.

JORDÃO. F. (1998). Uma abordagem cognitiva das Organizações. Estudos de mapeamento cognitivo na banca portuguesa. Porto: FPCE - UP.

KATZ D. \& KAHN, R (1987). Psicologia social dos organizaçōes (3ª Ed.). São Paulo: Editora Atlas.

KELLY, G. A. (1963). A theory of personality. The Psychology of Personal Constructs. New York. NY: W.W. Norton \& Company.

LORD, R. G. \& KERNAN, M. C. (1987). Scripts as determinants of purposeful behavior in organizations. Academy of Management Review. 12 (2), 265-277.

MCGREGOR, D. (1960). The human side of enterprise (International Student Edition). Tokyo: McGraw-Hill Book Company, Inc..

MINTZBERG, H. (1982). Structure et dynamique des orgonisations. Paris: Les Éditions d' Organisation. - Traduit par Pierre Romelaer -

MINTZBERG, H. (1990). Le management Voyage au centre des organisations. Paris: Les Éditions d' Organisation. - Traduit par Jean-Michel BEHAR .

MORGAN, G. \& RAMIREZ, R. (1983). Action learning: A holographic metaphor for guiding social change. Human Relations, 37 (1), 1-28.

MORGAN, G. (1980). Paradigms, metaphors, and puzzle solving in organization theory. Administrative Science Quarterly. 605-622.

MORGAN, G. (1983). More on metaphor: Why we cannot control tropes in administrative science. Administrative Science Quorterly, 28, 601-607.

MORGAN, G. (1986). Images of Organizotion. Beverty Hills, CA: SAGE Publications.

MORGAN, G. (1989). Imoges de I'Organisotion (Traduit de l'anglais par Solange Chevrier-Vouvé et Michel Audet). Québec: Les Presses de L' Université Laval, Éditions ESKA.

PAGĖS, M., BONETTI, M., DE GAULEJAC,V. \& DESCENDRE. D. (1984). L' emprise de l' organisa. tion ( $3^{\mathrm{A}} \mathrm{Ed}$.). Paris: Presses Universitaires de France. 
PEIRÓ, J. M. (1990). Organizaciones: Nuevos perspectivas psicosociológicos. Barcelona: PPU. Promociones y Publicaciones Universitarias, A.S.

SCOTT,W. R. (1987). Organizations: Rational, natural and open systems (2 ${ }^{\text {nd }}$ Ed.). Englewood Cliffs, NJ: Prentice-Hall International.

STERNBERG, RJ. (1985). Implicit theories of intelligence, creativity and wisdom, Joumal of Personality and Social Psychology, 49 (3), 607-627.

STUBBART, C. I. \& RAMAPRASAD, A. (1988). Probing two chiefs executives schematic knowledge of the U.S. Steel Industry using cognitive maps. In R. Lamb et P. Shrivastava (Dir.). Advances in Strategic Monogement (Vol. 5, pp. 139-164). Greenwich, CT.: JAl Press.

WALSH, J. (1989). Knowledge structures and the management of organizations: $A$ research review and agendo. Hanover: Amos Tuck School of Business Administration. (Paper).

WALSH, J. P. \& FAHEY, L ( 1986 ). The role of negotiated belief structures in strategy making. Journal of Management, 12 (3), 325-338.

WEICK, K. E. (1979). The social psychology of organizing (2 ${ }^{\text {nd }}$ Ed). New York: McGraw-Hill, Inc.

WEICK, K. E. (1982). Enactment processes in organizations. In B. M. Staw \& G. R. Salancik (Eds.). New Directions in Organizational Behoviour (Cap. 8, pp. 267-300). Malabar: R E. Krieger Publishing Company.

WEICK, K. E. (1990). Cartographic myths in organizations. In Huff, A. S. (Ed.). Mapping Strategic Thought (Introduction, pp. 1-10). West Sussex, England: John Wiley \& Sons Ltd..

WEICK, K. E. (1995). Sensemaking in organizotions. Thousand Oaks, CA: SAGE Publications, Inc.. YIN, R. K. (1993). Applications of case study research. Newbury Park, CA: SAGE Publications.

YIN, R. K. (1994). Cose study research: Design and methods (2 ${ }^{\text {nd }}$ Ed). Thousand Oaks, CA: SAGE Publications. 
(Página deixada propositadamente em branco) 
Série

Investigação

Coimbra

Imprensa da Universidade

2000 